\title{
И.В. Абанкина
}

Институт развития образования, Национальный-исследовательский университет Высшая школа экономики, Москва

\section{Финансирование образования: тренд на персонализацию}

Аннотация. В статье анализируется соотношение объемов финансирования высшего образования в России и зарубежных странах. Показано, что в России при схожей с другими странами структуре расходов их стоимостные значения в три раза отстают от уровня стран ОЭСР. На основе обобщения зарубежного опыта реформ в управлении финансированием высшего образования выявлены основные тенденции в финансировании российского высшего образования: концентрация поддержки университетов-лидеров, опора на государственное финансирование высшего образования как основной источник, слабое использование механизмов частно-государственного партнерства и доходов от фондов целевого капитала. Основное внимание в статье уделено переходу к инвестиционной модели финансирования образования с передачей права распоряжения ресурсами на принципах персонализации, включая такие инструменты, как контракты на основе результативности, конкурентные фонды и ваучеры, основанные на заслугах, контракты на человеческий капитал, а также индивидуальные образовательные счета как персональный инвестиционный ресурс. Именно эти механизмы начинают играть ключевую роль в ресурсном обеспечении развития образования.

Ключевые слова: финансирование высшего образования, расходына образование, финансовые ограничения, диверсификаиия доходов.

Классификация JEL: H52, I22, I23.

DOI: $10.31737 / 2221-2264-2019-41-1-11$

Многие страны сталкиваются с проблемой ограниченного государственного финансирования и предпринимают усилия по приоритетной поддержке конкурентоспособных образовательных программ. Особенно ощутимо сокращение государственного финансирования чувствуется после долгих лет традиционной опоры именно на этот источник (Knight, 2011; Douglass, 2012). Исследователи заняты поиском баланса между внешними условиями функционирования университетов (такими как платежеспособный спрос населения, модерни- зация системы управления, финансирование по результатам деятельности) с внутренними характеристиками, отражающими оптимизацию внутренней структуры университета и переход на принципы ответственного финансового менеджмента. Как показывают расчеты, в России государственные расходы на образование сокращались как в реальном выражении (табл. 1), так и в процентах ВВП (табл. 2), динамика в образовании имеет нисходящий тренд в отличие от динамики в таких сферах, как здравоохранение и социальная политика.

таблица 1

Расходы консолидированного бюджета Российской Федерации и бюджетов государственных внебюджетных фондов в сопоставимых ценах, 2012-2016 гг., млрд руб.

\begin{tabular}{|l|c|c|c|c|c|c|}
\hline \multicolumn{1}{|c|}{ Сфера } & 2012 & 2013 & 2014 & 2015 & 2016 & $2016 / 2012$ \\
\hline \hline Образование & 2558,36 & 2757,24 & 2662,07 & 2459,23 & 2427,15 & $95 \%$ \\
\hline $\begin{array}{l}\text { Культура, } \\
\text { кинематография }\end{array}$ & 340,21 & 359,789 & 376,49 & 365,81 & 330,67 & $97 \%$ \\
\hline Здравоохранение & 2283,35 & 2212,44 & 2325,73 & 2645,37 & 2443,80 & $107 \%$ \\
\hline Социальная политика & 7730,90 & 8358,45 & 8083,81 & 9689,93 & 8536,70 & $110 \%$ \\
\hline $\begin{array}{l}\text { Физическая культура } \\
\text { и спорт }\end{array}$ & 186,74 & 209,30 & 232,89 & 235,67 & 205,13 & $110 \%$ \\
\hline
\end{tabular}


Таблица 2

Динамика расходов на социальную сферу в 2012-2016 гг., \% к ВВП

\begin{tabular}{|l|c|c|c|c|c|}
\hline \multicolumn{1}{|c|}{ Сфера } & 2012 & 2013 & 2014 & 2015 & 2016 \\
\hline \hline Образование & 3,82 & 4,07 & 3,83 & 3,65 & 3,61 \\
\hline Культура, кинематография & - & 0,53 & 0,52 & 0,48 & 0,49 \\
\hline Здравоохранение & 3,41 & 3,26 & 3,20 & 3,44 & 3,63 \\
\hline Социальная политика & 11,55 & 12,33 & 11,12 & 12,59 & 12,68 \\
\hline Физическая культура и спорт & 0,28 & 0,31 & 0,32 & 0,31 & 0,30 \\
\hline
\end{tabular}

Источники: данные Федерального казначейства (http:/ / www.roskazna.ru/).

\section{Начиная с 2010 г. политика России} в сфере высшего образования направлена на резкую активизацию интеграционных процессов - объединение финансовых, материальнотехнических и интеллектуальных ресурсов университетов, колледжей и научных институтов. По замыслу чиновников реструктуризация должна способствовать повышению качества подготовки студентов и обеспечению их конкурентоспособности на рынке труда. Однако бюджетные ограничения заметно деформировали указанную политику, усилив концентрацию инвестиций на точках роста. Начиная с 2015 г. более $40 \%^{1}$ субсидий на государственное задание вузов, подведомственных Минобрнауки, было распределено между 35 федеральными и национальными исследовательскими университетами, среди которых 15 вузов-участников программы повышения международной конкурентоспособности «Проект 5-100». Остальные 260 университетов системы Минобрнауки ежегодно получают менее $60 \%$ общего объема государственной субсидии. Столь высокая концентрация средств создает системные угрозы: для значительного числа региональных вузов это означает сворачивание деятельности, а для вузов-лидеров объемы поддержки оказываются недостаточными - они в 2-3 раза превышают бюджетную субсидию остальным вузам и в то же время в 2-3 раза проигрывают по объему финансирования среднеевропейским университетам.
В ряде стран (Великобритания, США, ЮАР, Финляндия, Австрия) в сфере высшего образования уже прошли волны слияний (merge) и поглощений (acquisition), накоплен определенный опыт (Gale, 2010). У российских вузов опыт в этой сфере пока весьма ограничен. Несмотря на усилившуюся тенденцию к финансовой независимости, доля государственных средств в бюджетах большинства вузов стран Западной Европы сохраняется на уровне $70 \%$, в России $-55,8 \%^{2}$. В условиях экономического спада правительства разных стран приняли радикальные меры по уменьшению бюджетных расходов на высшее образование. Это привело к сокращению заработной платы и социальных льгот для преподавателей в вузах таких стран, как Нидерланды, Италия и Венгрия. В других странах (Ирландия, Греция) бюджетные ограничения повлекли еще и уменьшение финансирования для поддержания и развития университетской инфраструктуры (EUA, 2014). Меняются отношения между государством и институтами высшего образования путем передачи ответственности за рост, инновации и диверсификацию самим университетам. При этом на государственных институтах остаются функции установления общих направлений развития в сфере высшего образования, его финансирования (Kaiser et al., 2014). В зарубежных исследованиях приводятся свидетельства связи финансовой автономии университетов с повышением их эффек-

\footnotetext{
${ }^{1}$ Источник: Единая информационная система обеспечения деятельности Минобрнауки России (http://eis.mon.gov. ru), расчеты автора.

${ }^{2}$ Источник: данные Единой информационной системы обеспечения деятельности Минобрнауки России. Форма ФСН № ВПО-2 по Российской Федерации. Средства федерального бюджета - 53,0\%, региональных бюджетов - 2,7\%, местных бюджетов $-0,1 \%$.
} 
тивности (Aghion et al., 2010). Таким образом, зарубежные страны пытаются расширить базу финансовой поддержки высшего образования и гибкость системы, а не проводить политику концентрации усилий исключительно на поддержке лидеров, как это делается в России.

В России, как показали исследования, уже столкнулись с проблемой ограниченности платежеспособного спроса на качественное образование, в том числе и высшее образование, причем практически во всех доходных группах. Несмотря на то что доля средств населения в доходах университетов достаточно высока, тем не менее только $31 \%$ семей с одним ребенком расходуют средства на высшее образование и $8,7 \%$ семей - с двумя и более детьми (рис. 1). Это означает, что менее $40 \%$ семей реально участвуют в софинансировании высшего образования в России, фактически Россия имеет самую низкую по сравнению с другими странами долю населения, способного оплачивать образование.

Как показали опросы, проводимые НИУ ВШЭ (Двенадцать решений..., 2018, с. 17-18) в рамках подготовки «Стратегии развития человеческого капитала», практически

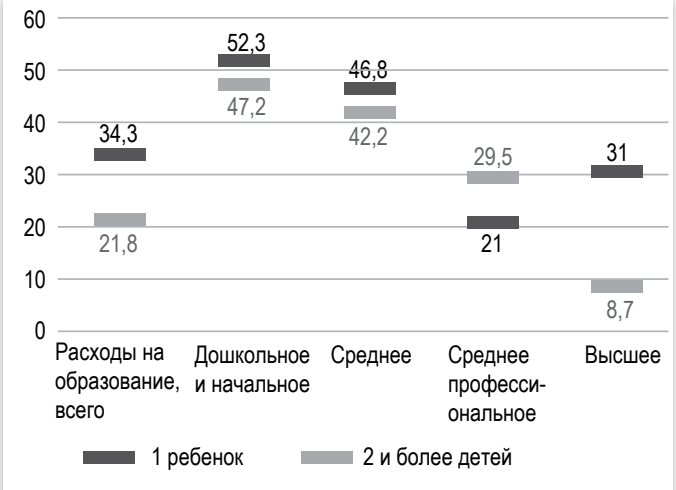

Рис. 1

Доля семей, имеюших расходы на образование в структуре бюджетов домашних хозяйств, в зависимости от числа детей в семъе, \% (по уровням образования)

Источники: распределение расходов домашних хозяйств на оплату услуг в системе образования по домашним хозяйствам с различным числом детей по 20\%-ным группам населения с различным уровнем среднедушевых располагаемых ресурсов в 2016 г. (по итогам выборочного обследования бюджетов домашних хозяйств; в процентах) (Росстат, 2016).
КАКОЙ ИЗ ЭТИХ ВАРИАНТОВ ВЫ БЫ ПРЕДПОЧЛИ?

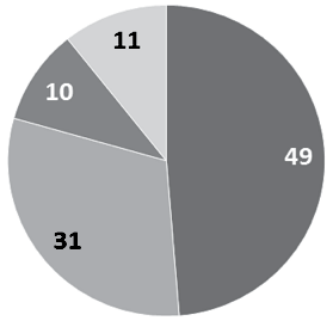

Получать самому и давать своим детям бесплатное образование стандартного качества

Получать самому и давать своим детям образование более высокого качества, доплачивая 5\% дохода вашей семьи

Получать самому и давать своим детям самое качественное образование, доплачивая 15\% дохода вашей семьи

Затруднились ответить

Рис. 2

Ответ на вопрос «Какой из этих вариантов въ бы предпочли?», \% опрошенных

половина опрошенных не готова доплачивать за образование, невзирая на его качество (рис. 2). Тем самым можно констатировать серьезные проблемы с введением механизмов расширения финансовой поддержки высшего образования за счет населения без компенсаторных инструментов и повышения гибкости системы для участия семей с разным составом и доходами.

\section{Бюджетирование, ориентированное на результат}

Общим вектором, определяющим реформирование системы финансирования университетов, стало бюджетирование, ориентированное на достижение целей, определенных в государственных заданиях (контрактах) в рамках среднесрочного планирования. Примером могут служить вузы Дании и Швеции, в которых действуют контракты на основе результативности (performance contracts). Ежегодный контроль за әффективностью расходования выделенных по контракту средств осуществляется в Швеции под руководством Национального ревизионного управления. Контрактная система, подобная шведской, действует в Финляндии. Схожие механизмы реализуются в Венгрии при использовании конкурсных механизмов распределе- 
ния ресурсов в высшем образовании - конкурентные фонды (competitive funds) и ваучеры, основанные на заслугах (merit-based vouchers). Во Франции осуществлен переход на систему среднесрочных контрактов, в основе которых лежат согласованные со стороны государства и университетов планы институционального развития. В Нидерландах и Чешской Республике размер фонда для обучения напрямую зависит от результатов, достигнутых по основным показателям (EUA, 2015). Строгая экономия финансовых ресурсов подводит большинство стран к снятию части бремени с государства и неизбежности диверсификации доходов и форм распределения ресурсов. Для оптимизации государственных расходов в вузах некоторых стран проводится сокращение аудиторной нагрузки в пользу самостоятельной работы студентов. Данные изменения в учебном процессе приводят к снижению нагрузки на преподавателей, а значит, снижению их заработной платы. При этом высвободившиеся средства перенаправляются на оснащение библиотек, обновление оборудования. Такая стратегия развития ориентирована на привлечение инвестиций в высшее образование с использованием контрактной системы на основе результативности.

\section{Инвестиционные модели распределения ресурсов: тренд на персонализацию}

Для привлечения личных средств граждан, негосударственных средств, а также фондов и источников других негосударственных институтов в сферу высшего образования многие страны нацелены на использование инновационных моделей распределения ресурсов с применением различных финансовых и нефинансовых инструментов (Agasisti, Wolszczak-Derlacz, 2015). К примеру, в Великобритании есть возможность создавать персональные Интернет-страницы, призванные аккумулировать в одном месте информацию о достижениях и грантах человека, полу- ченных им в течение жизни (lifelong learning accounts $^{3}$ ). Данная модель призвана стимулировать индивидуальную приверженность к обучению, она позволяет на протяжении всей жизни проводить прогрессивную образовательную стратегию. В Австралии, финансовым инструментом привлечения личных средств граждан в сферу высшего образования служат набирающие популярность контракты на человеческий капитал (human capital contracts), представляющие собой прямые инвестиции в человеческий капитал: инвестор платит за обучение студента, а тот, в свою очередь, обязуется после окончания обучения отдавать инвестору фиксированную долю своего будущего заработка. Такого вида контракты более привлекательны для студентов, чем традиционные студенческие займы, поскольку погашение средств проводится не по определенной процентной ставке, а зависит от заработка студента. Таким образом, студент получает финансирование в обмен на процент от своего дохода в течение фиксированного периода времени. По мнению специалистов, использование данного финансового инструмента позволит улучшить әффективность рынка высшего образования (The Global Viability..., 2015). Фактически зарубежные страны пытаются расширить возможности для студентов, домохозяйств и бизнеса инвестировать в сферу образования.

\section{Эндаумент, или целевой капитал}

Одним из эффективных финансовых инструментов, обеспечивающих стабильность, является эндаумент (endowment), или целевой капитал, как его назвали в России. В западных странах эндаумент - это неделимый инвестиционный актив в виде денег, ценных бумаг, недвижимого и иного имущества, передаваемых некоммерческим организациям юридическими или физическими лицами в качестве благотворительной помощи. К примеру, в Гарвардском университете доля доходов от әндаумента составляла $32 \%$ всего совокупного дохода, доходы от платы за обучение оцени-

\footnotetext{
3 См. материалы сайта https://www.gov.uk/government/uploads/system/uploads/attachment_data/file/349987/LLA_
} Additional_Guidance.pdf. 
вались в пределах 20\%, доля правительственных грантов и контрактов - 18\%, доля неправительственных грантов и контрактов $-4 \%$, прочие доходы - 26\% (Harvard University..., 2012). В Стэнфордском университете в 2013 г. на долю доходов от исследований приходилось $28,1 \%$, причем $83 \%$ исследований поддерживало федеральное правительство, $21 \%$ доходов университета - это доходы от эндаумента, а доходы от оплаты за обучение составляли 16\% (Stanford Facts, 2013.

По әкспертным оценкам, в России приток средств, полученных в результате развития фондов целевого капитала университетов, составляет около $1 \%$ общего объема средств организаций по всем источникам их получения, только МГИМО приближается по данному показателю к 3\% (Дьячкова, 2016). Отсутствие системных подходов, определяющих доходы от целевого капитала, снижает регулярность пожертвований, которые важны при планировании сумм расходования. Это свидетельствует о низком качестве финансового менеджмента в российских университетах по использованию современных технологий и методов управления доходами от целевого капитала, широко применяемых в зарубежных странах, основанных на норме расходования, учете инфляции, средней стоимости активов и других методах.

\section{Механизмы целевого финансирования}

Механизмы целевого финансирования направлены на расширение участия университетов в государственных (национальных) программах. К примеру, в Великобритании активно внедряются программы, затрагивающие развитие сети научных центров для школьников $\mathrm{STEM}^{4}$ (Science, Technology, Engineering, Mathematics - точные науки, технологии, инженерия и математика), а также поощряется участие в софинансировании образовательных организаций с введением Национальной стипендиальной программы ${ }^{5}$ (National Scholarship
Programme). Во Франции в ситуации ухудшения инфраструктуры и финансового состояния университетов предложены инициативы в рамках национальной программы Operation, ориентированной на обновление действующих кампусов посредством значительных целевых инвестиций.

Проводятся инициативы по формированию сети элитных университетов, создающие стимулы к институциональным изменениям и способствующие развитию научной работы в вузах: усилению кадровой составляющей вузовской науки, обновлению оборудования, участию вузов в технологических платформах. К примеру, в Германии запущена инициатива German Excellence Initiative, целью которой является усиление передовых исследований, а также повышение качества исследовательских институтов в университетах. В Гейдельбергском университете на долю целевого финансирования от Немецкого исследовательского фонда приходится более 15\% доходов, а со стороны немецких промышленников около 6\% (Universität Heidelberg, 2012). Мюнхенский технический университет на научные исследования получает более $10 \%$ целевого финансирования от Немецкого исследовательского фонда и более $6 \%$ за счет средств частных промышленников (Technische Universität München, 2012). В Нидерландах университеты получают дополнительные целевые субсидии на реализацию научных инновационных проектов из Голландского исследовательского совета и Нидерландской королевской академии искусств и наук.

Аналогичные программы развернуты и в России. В частности, к ним относятся программы развития ведущих классическихуниверситетов, прикладные научные исследования в вузах медицинского профиля, федеральные целевые программы «Научные и научно-педагогические кадры инновационной России» на 2014-2020 гг. и «Исследования и разработки по приоритетным направлениям развития

\footnotetext{
${ }^{4}$ См. материалы сайта http://www.stemnet.org.uk/about-us/.

5 Для студентов, начинающих обучение в вузах в 2015-2016 гг., участие в Национальной стипендиальной программе не предусмотрено.
} 
научно-технологического комплекса России на 2014-2020 годы». Практически неизменными остались объемы ассигнований из федерального бюджета на реализацию мероприятий программы фундаментальных научных исследований в Российской Федерации на долгосрочный период (2013-2020 гг.). В целом позитивная динамика финансирования отмечается и по программе повышения международной конкурентоспособности «Проект 5-100».

\section{Повышение платы за обучение и активизация домохозяйств}

В некоторых европейских странах многие вузы пошли по пути существенного увеличения платы за обучение (Великобритания, Испания, Чешская Республика и др.). При этом бюджетная политика подкрепляется позицией перехода к расширенным образовательным кредитам для поддержания участия домохозяйств в софинансировании образования. К примеру, в Великобритании увеличены объемы образовательных кредитов, а также грантов на поддержание жизненного уровня студентов дневной формы обучения, введено кредитование для студентов заочной формы обучения, призванных покрыть возросшую плату за обучение. В Чешской Республике при отсутствии средств на обучение предусмотрен банковский кредит с возвратом денег в течение 15 лет от того момента, когда заработная плата должника достигнет среднего уровня по стране. Финансовая поддержка студентов в Норвегии основана на стипендиях и займах на образование из Государственного банка.

В России образовательные кредиты не получили широкого распространения в силу строгих требований банковской системы к обоим родителям (из-за того что абитуриенты не достигли совершеннолетия) по гарантиям обеспечения возвратности кредита, отсутствия гибких механизмов по уплате процентов после окончания вуза в ситуации потери работы, отпуска по уходу за ребенком или службы в армии. Для успешной реализации кредитной формы финансирования высшего образования требуется стабильность банковской системы и уверенность домохозяйств в будущих заработках на долгосрочный период. Фактически предлагаемая на сегодняшний момент схема кредитования соответствует возможностям семей, которые могут оплачивать высшее образование без заемных средств, а семьи с более низким уровнем дохода отличаются высоким уровнем нестабильности своего финансового положения и не рискуют брать долгосрочные кредиты.

На протяжении 1995-2005 гг. общественный спрос на профессиональное образование в России рос очень высокими темпами. Тенденцию этого десятилетие можно с уверенностью охарактеризовать как экстенсивный рост на расширяющемся образовательном рынке. Вместе с тем, начиная с 2006 г. тенденция постепенно меняется. Сначала изменения затронули негосударственные вузы, а с 2007 г. они охватили и сектор государственного профессионального образования. Основными причинами, вызвавшими резкое снижение общественного спроса на профессиональное образование, стали два ключевых фактора демографический спад и финансовый кризис (Балацкий, 2014). Два неблагоприятных фактора, действующие одновременно, ускорили и усилили эффект: образовательный рынок быстро потерял набранный темп роста, а затем в очень сжатые сроки из расширяющегося превратился в сжимающийся рынок (Abankina, Filatova, 2015).

Доходы университетов от выполнения договорных работ на НИР и НИОКР по заказу предприятий и бизнес-корпораций тоже не показывают тенденции к восстановлению докризисного уровня (Абанкина и др., 2016). Университеты Москвы и Петербурга аккумулируют объемы внебюджетных доходов, практически равные суммарным доходам вузов, расположенных во всех остальных регионах России. На ближайшие 10 лет бюджетная политика ужесточается, возрастают требования к сокращению бюджетного дефицита. На первый план выходят другие приоритеты бюджетной политики, в частности пенсионная реформа. Расходы университетов на содержание имущественного комплекса и эксплуатации дорогостоящего оборудования, приобретенного на 
предыдущем этапе, будут возрастать из-за роста тарифов, расходов на ремонт и т.п. В результате университеты снова окажутся в ситуации хронического недофинансирования, не имея стабильных источников покрытия финансового дефицита.

Нехватка средств подталкивает российские вузы к следующим сценариям развития:

- либо выполняется әффективный контракт с профессорско-преподавательским составом (ППС), но при этом под угрозой недофинансирования остается имущественный комплекс, его содержание и развитие;

- либо выполняются обязательства по содержанию имущественного комплекса и материального обеспечения учебного процесса, но тогда выделенные бюджетные ассигнования не позволяют перейти к әффективному контракту ППС.

Одним из выходов в сложившейся ситуации может послужить изменение политики распределения финансовых ресурсов в сфере высшего образования в условиях сжимающегося рынка, а именно пересмотр пропорции финансовой поддержки государством вузовлидеров и региональных вузов в пользу последних. Процесс оптимизации будет идти в России неравномерно как в динамике, так и в территориальном разрезе. В условиях кризиса региональным вузам, имевшим сильные позиции в условиях экономического роста, необходимо будет пересмотреть свою политику. Сейчас они теряют контингент платных студентов, а отсутствие тесных связей с работодателями для трудоустройства выпускников не позволяет им использовать современный менеджмент с опорой на партнерство. Полезной может оказаться практика, распространенная в коммерческом секторе (управление рисками, управление исследовательским портфолио и т.п.). Однако указанные практики необходимо адаптировать к специфике деятельности и академическим ценностям образовательных организаций. Расширение доходных источников финансирования вузов должно учитывать изменения структурной динамики в высшем образовании, которые связаны с демографическим спадом; изменениями правил приема в вузы; нестабильностью платежеспособного спроса; усилением конкуренции вузов, в том числе за ресурсы в условиях сокращения государственного финансирования.

Предыдущая индустриальная модель, которая основывалась на стандартизации образования и обеспечения его доступности за счет создания сети учреждений, транслирующих подготовку кадров, уходит в прошлое. Для нее были характерны принципы сметного финансирования и управления затратами. Поддерживало такую модель репетиторство за счет семейных ресурсов, но прямого участия семей в финансировании высшего образования индустриальная модель не предусматривала. В современных условиях роста вклада человеческого капитала в экономику упор делается на повышение академической мобильности, прозрачности в распределении общественных ресурсов для поддержки длительных образовательных треков, активное вовлечение ресурсов семей и работодателей. Поиск баланса интересов стейкхолдеров в развитии высшего образования сопряжен с глобализацией, созданием образовательных платформ, работающих на искусственном интеллекте. Это означает переход к инвестиционной модели финансирования образования на основе венчурного капитала, управления результатами и передачей права распоряжения ресурсами на принципах персонализации.

\section{ЛИТЕРАТУРА}

Абанкина И.В., Винарик В.А., Филатова Л.М. (2016). Государственная политика финансирования сектора высшего образования в условиях бюджетных ограничений // Журнал Новой экономической ассочиащии. № 3 (31). С. 110-143.

Балацкий Е.В. (2014). Синдром аритмии реформ в системе высшего образования // Журнал Новой экономической ассоиииаиии. № 4 (24). С. 111-140.

Двенадцать решений для нового образования (2018). Доклад Центра стратегических 
разработок и Высшей школы экономики. Москва. С. 17-18.

Дьячкова Э.А. (2016). Управление доходами от целевого капитала в университетах / / Вопросы образования. № 1. С. 225-244.

Abankina I., Filatova L. (2015). Sustaining Student Enrolment: Impact of Demand Trends for Higher Education in Russia / / Journal of US-China Public Administration. Vol. 12(5). P. 345-359.

Agasisti T., Wolszczak-Derlacz J. (2015). Exploring Efficiency Differentials between Italian and Polish Universities, 2001-11 / / Science and Public Policy.

Aghion P., Dewatripont M., Hoxby C., MasColell A., Sapir A. (2010). The Governance and Performance of Universities: Evidence from Europe and the US / / Economic Policy. Vol. 25 (61). P. 7-59.

Douglass J. (2012). Money, Politics and the Rise of For-Profit Higher Education in the US: A Story of Supply, Demand and the Brazilian Effect. Center for Studies in Higher Education.

EUA (2014). EUA Public Funding Observatory 2014. Brussels: European University Association.

EUA (2015). DEFINE Thematic Report: Performance-Based Funding of Universities in Europe. Brussels: European University Association.

Gale S.E. (2010). Mergers and Acquisitions as Instruments of Strategic Change in Higher Education: Assessment Measures and Perceptions of Success. University of Pennsylvania.

Harvard University Fact Book 2011-12 (2012). The Office of Institutional Research. Cambridge: Holyoke Center, President and Fellows of Harvard College.

Kaiser F., Maassen P., Meek L., Vught F. van, Weert E. de, Goedegebuure L. (2014). Higher Education Policy: An International Comparative Perspective. Elsevier.

Knight J. (2011). Financing Access and Equity in Higher Education. Center for International Higher Education, Boston College, USA.
Stanford Facts (2013). [Электронный ресурс] Research. Режим доступа: http://facts. stanford.edu/research/, свободный. Загл. с экрана. Яз. англ. (дата обращения: декабрь 2018 г.).

Technische Universität München (2012). Finanzierung: Universität Budget in das Geschäftsjahr.

The Global Viability of Human Capital Contracts (2015). The Roosevelt Institute Center on International Development, Yale University.

Universität Heidelberg (2012). [Электронный ресурс] Finanzierung 2012. Режим доступа: http://www.uni-heidelberg.de/ university/statistics/funding.html, свободный. Загл. с экрана. Яз. англ. (дата обращения: декабрь 2018 г.).

Wolff E.N., Baumol W.J., Saini A.N. (2014). A Comparative Analysis of Education Costs and Outcomes: The United States vs. other OECD Countries / / Economics of Education Review. Vol. 39. P. 1-21.

Поступила в редакиию 15 декабря 2018 г.

REFERENCES (with English translation or transliteration)

Abankina I., Filatova L. (2015). Sustaining Student Enrolment: Impact of Demand Trends for Higher Education in Russia. Journal of US-China Public Administration, 12 (5), 345-359.

Abankina I.V., Filatova L.M., Vynaryk V.A. (2016). State Policy of Higher Education Sector Financing under the Budgetary Constraints. Journal of the New Economic Association, 3 (31), 111-143.

Agasisti T., Wolszczak-Derlacz J. (2015). Exploring Efficiency Differentials between Italian and Polish Universities, 2001-11. Science and Public Policy.

Aghion P., Dewatripont M., Hoxby C., MasColell A., Sapir A. (2010). The Governance and Performance of Universities: Evidence from Europe and the US. Economic Policy, 25 (61), 7-59. 
Balatsky Ye.V. (2014). Syndrome of Reforms' Arrhythmia in the Higher Education. Journal of the New Economic Association, 4 (24), 111-140.

Bruckmeier K., Wigger B.U. (2014). The Effects of Tuition Fees on Transition from High School to University in Germany. Economics of Education Review, 41, 14-23.

D’jachkova E.A. (2016). Revenue Management of Endowments in Universities. Educational Studies, 1, 225-244.

Douglass J. (2012). Money, Politics and the Rise of For-Profit Higher Education in the US: a Story of Supply, Demand and the Brazilian Effect. Center for Studies in Higher Education.

EUA (2014). EUA Public Funding Observatory 2014. Brussels: European University Association.

EUA (2015). DEFINE Thematic Report: Performance-Based Funding of Universities in Europe. Brussels: EUS (European University Association).

Gale S.E. (2010). Mergers and Acquisitions as Instruments of Strategic Change in Higher Education: Assessment Measures and Perceptions of Success. University of Pennsylvania.

Harvard University Fact Book 2011-12 (2012). The Office of Institutional Research. Cambridge: Holyoke Center, President and Fellows of Harvard College.
Kaiser F., Maassen P., Meek L., Vught F. van, Weert E. de, Goedegebuure L. (2014). Higher Education Policy: An International Comparative Perspective. Elsevier.

Knight J. (2011). Financing access and equity in higher education. Center for International Higher Education, Boston College, USA.

Stanford Facts (2013). Research. Available at: http:/ / facts.stanford.edu/research / (accessed: December 2018).

Technische Universität München (2012). Finanzierung: Universität Budget in das Geschäftsjahr.

The Global Viability of Human Capital Contracts (2015). The Roosevelt Institute Center on International Development, Yale University.

Twelve New Solutions for Education (2018). Report of the Centre for Strategic Research and Higher School of Economics. Moscow, 17-18.

Universität Heidelberg (2012). Finanzierung. Available at: http://www.uni-heidelberg. $\mathrm{de} /$ university/statistics / funding.html (accessed: December 2018).

Wolff E.N., Baumol W.J., Saini A.N. (2014). A Comparative Analysis of Education Costs and Outcomes: The United States vs. other OECD Countries. Economics of Education Review, 39, 1-21.

Received 15.12.2018

\section{I.V. Abankina}

Institute for Education Studies of National Research University Higher School of Economics, Moscow, Russia

\section{Financing of Education: Trend on Personalization}

Abstract. This article analyzes the ratio of funding higher education in Russia and foreign countries. It is shown, that at a similar cost structure in Russia compared to other countries, and their monetary value is three times behind the level of the OECD countries. On the basis of generalization of foreign experience of reforms in the management of the financing of higher education research identified the major trends in the financing of Russian higher education: university leaders support concentration, reliance on public higher education financing as the main source, poor use of publicprivate partnership arrangements and income from funds of the trust capital. The focus of the article is on the transition to investment financing models of education transfer management of resources based on principles of personalization, including such tools as performance based contracts, competitive funds and vouchers, based on merit, human capital contracts, as well as individual educational accounts (lifelong learning accounts) as personal investment resource. It is these mechanisms that begin to play a key role in the resource development of education. 
Keywords: higher education financing, universities' fiscal policy, expenses on education, financial restrictions, income diversification.

JEL Classification: H52, I22, I23.

DOI: $10.31737 / 2221-2264-2019-41-1-11$

\section{А.Я. Рубинштейн}

Институт экономики РАН, Государственный институт искусствознания,

Журнал НЭА,

\section{O государственных инвестициях в гуманитарном секторе экономики}

Аннотация. Представлены теоретико-методологическое обоснование принципиально нового подхода и соответствующая ему методика определения объема государственных инвестиций производителям опекаемых благ в гуманитарном секторе. В ее основе лежит оценка дефицита дохода этих организаций с учетом объективных экономических закономерностей, определяющих условия их деятельности, и социальных норм, устанавливаемых государством. В качестве социальных норм рассмотрены уровень покупательной способности потребителей опекаемых благ (через механизм цен на эти товары и услуги) и работников организаций гуманитарного сектора экономики (через механизм оплаты их труда). Тестирование предложенной модели показало, что объем фактических бюджетных субсидий организациям гуманитарного сектора оказался значительно ниже их модельной величины и был явно недостаточным, обусловив тем самым нежелательные процессы коммерциализации, сопровождаемые сверхинфляционным ростом цен на опекаемые блага и снижением их доступности для населения.

Ключевые слова: опекаемье блага; инвестииин; человеческий капитал; «болезнъ иен»; отставание производительности труда; нормативнье затрать;; дефииит дохода; субсидия; индексы иен.

Классификация JEL: C43, L38, Z1, Z11.

DOI: $10.31737 / 2221-2264-2019-41-1-12$

\section{1. Теоретические предпосылки}

В качестве предпосылки исследования используется положение о существовании интереса общества как такового, не сводимого к предпочтениям экономических агентов (Grinberg, Rubinshteyn, 2005; Гринберг, Рубинштейн, 2013). Этот важный в методологическом плане концепт на первый взгляд противоречит принципу методологического индивидуализма. Однако более внимательный анализ позволяет увидеть условность данного заключения. Дело в том, что в его основе лежит не высказанное, но весьма существенное условие.

Речь идет о наличии совершенной институциональной среды - своеобразного аналога невидимой руки, в которой действуют рациональные экономические агенты. В этом случае интересы индивидуумов, взаимодействующих с другими экономическими агентами и институтами, гармонизируются и трансформируются в совершенной институциональной среде в интерес общества как такового. Иначе говоря, тезис о сводимости преференций общества к предпочтениям индивидуумов тождествен предпосылке о наличии совершенной институциональной среды.

Ситуация меняется, если эта гипотеза не получает подтверждения. В этом случае нет оснований утверждать, что интересы своекорыстных индивидуумов трансформируются в их совокупный интерес, являющийся интересом общества как такового. В реальном мире нет совершенных институциональных условий, когда механизмы саморегулирования способны действовать безошибочно, гармонизируя интересы общества и экономических агентов. Поэтому есть основания исследовать другую природу общественного интереса и рассматривать государство с его предпочтениями 